\title{
Human Factors in Fire Safety Measures
}

\author{
Ai Sekizawa \\ National Research Institute of Fire and Disaster, Japan \\ (Department of Chemical System Engineering, The University of Tokyo)
}

As introduced, my name is Ai Sekizawa and I serve as a visiting professor for the Fire and Disaster Management Engineering Laboratory at The University of Tokyo, as well as staff at the National Research Institute of Fire and Disaster. Today, I would like to talk about human factors in fire safety measures.

It is understood that fire is a disaster significantly involving human factors;

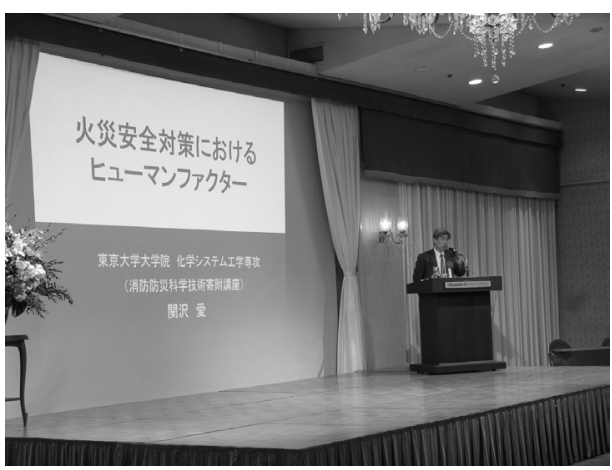

Photo 2.6.1 Prof. Sekizawa however, what is generally observed is that human aspects are involved in escape activities. Although my presentation today will focus on escape activities, there are other elements. Disasters or accidents are generally related to human error, and I would like to examine fire as a disaster from the viewpoint of human factors.

This photo of fireworks does not appear to pose a threat; however, the entire mountain is on fire; a very large area is burning. The appearance itself should normally impress you as a mountain fire. As many might know, this is the burning of dead grass on Mt. Wakakusa. It is well known to people living in the Kansai area as an event in January, the burning of the mountain is under human control. Burning of dead grass is an event not limited to Mt. Wakakusa but takes place

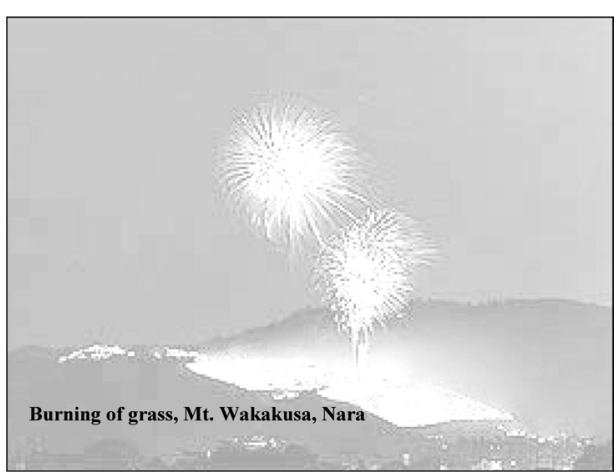

Figure 2.6.1 throughout the country; some festivals are held with large flames called "donto-yaki."

I mentioned this because humans have used fire since the onset of civilization. Fire is still used in a number of ways in factories, industries, internal combustion engines, cookeries, etc. Fire itself is universal and not necessarily dangerous on its own. Fire does not become a fire disaster until used under certain conditions. Fire disasters have social aspects and human factors. 
In fact, a definition of fire is provided. As you know, the Fire Defense Agency, Ministry of Public Management, Home Affairs, Posts and Telecommunications, collects fire reports on each fire in Japan for public information. There are many types of fire ranging from an infinitely small accident. Therefore, it is necessary to determine the levels of fire for collection in fire reports, and a definition of fire is given in the "Fire Report Instruction Manual." The manual defines fire as "a phenomenon of combustion that is generated or spread against human intention or generated by arson and that requires extinction or use of fire control equipment or something with similar effects or is a phenomenon of spread explosion." Explosion has been recognized as combustion and expressly included as fire in fire reports since 1959 even if its combustion is not externally visible.

The characteristic of this definition is first of all that fire is generated or spread against human intention (including arson). A fire started for one's use is not a fire disaster or a fire that can be left unattended is not a disaster. Also, "a phenomenon of combustion that requires extinction or use of fire control equipment or something with similar effects" means that references to size are included in this description. For example, it is not required to report a fallen cigarette ash that was put out with a dishrag to the Fire Defense Agency. Fire entails a certain degree of firefighting action as a fire disaster, such as serious use of a fire extinguisher or water bucket. Fire itself is a simple phenomenon of combustion or explosion in a physiochemical sense. However, fire disasters have social aspects, which are phenomena of combustion that cause damage to society.

Many human factors are involved in each phase of fire development; human errors are included in the cause of the fire itself. Arson is specifically a human act. Human aspects are involved in disaster prevention factors even during the phase of a spreading fire/smoke diffusion because opening/closing of fire doors or activation of a fire prevention system may not be automatic. Also, building occupants may notice an abnormality and call an emergency number, sound the alarm, engage in initial firefighting, or call for evacuation and evacuate themselves till the fire department arrives to conduct full-scale firefighting and rescue operations. These are human activities. I would like to speak of these human activities and focus on evacuation. First, I would like to view the human aspects of fire according to fire statistics.

I may not have to elaborate on this chart, which is popular and shown in the fire statistics every year. It is a bar graph of the number of fire fatalities among 100,000 people grouped by age, indicating a conspicuously large number in the group 76 years old or older. The age of 75 years or older is called "old old," at which one's declining physical strength and capacity are obvious, indicating a very high rate of fatality per population as was expected. On the other hand, a slightly large number is also seen in the infant age group. The absolute size of the group from elementary school children to 40 years old becomes slightly large because of their large population; however, almost 
no fatalities result from fire as seen in the rate of fatalities per population. Some risk is always involved, of course, because there are actually some cases of smoking in bed while being intoxicated; however, chances are that not many of those who are fit and healthy from 40 to 50 years old actually turn out to be a fatality. The aged and infants who fail to escape will result in fatalities. This is precisely because $90 \%$ of fires start in the home.

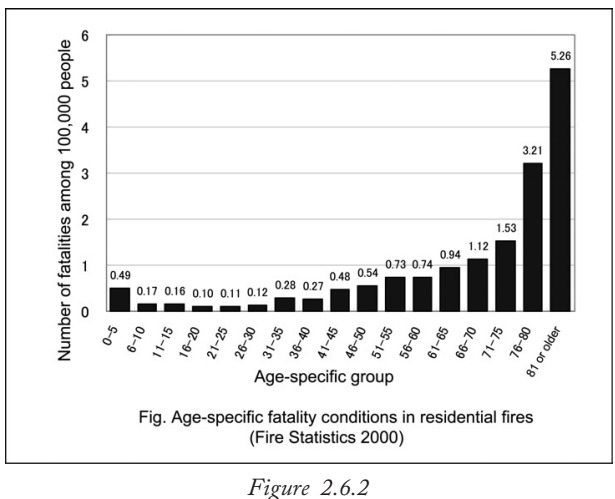

This chart shows the chronological changes in the population. The top dark portion represents the ratio of people at least 65 years old. This year is 2004. The dark portion increases in proportion to the aging of society as the year progresses from 2010 to 2015. On the other hand, people less than 64 years old are expected to decrease. Incidentally, a housing fire prevention campaign started in 1990, which ended in 2000, and a second housing fire prevention

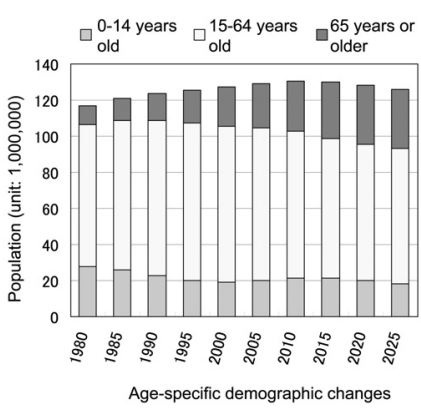

Figure 2.6.3 campaign has been started. A plan to revise the Fire Services Law was decided on March 8 of this year at the meeting of administrative vice ministers from several ministries and agencies, which will be submitted at the next Diet meeting. Installation of residential fire alarms will be mandatory; the mandatory installation will be implemented for new houses from the date of enforcement within 2 years after proclamation; existing houses in the period specified in the regulation for each local municipality. This was reported in the news today.

Now, this chart shows the projected changes in the number of fire fatalities from 1985 to 2025. Considering the ages of the population previously viewed and the higher rate of fire fatalities among older people, the number of fire fatalities may be expected to increase accordingly with the aging of the population if home fire prevention measures in 1985 remain the same. We estimated then that the number of fatalities (excluding those due to arson and suicide) at 1000 in 1985

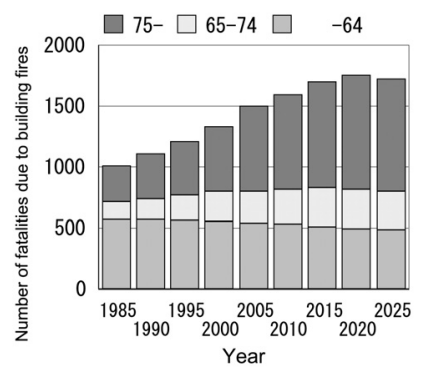

Projected changes in the number of fatalities due to building fires 
would be approximately 1700 in 2020 , more than half of which would be accounted for by those 75 years or older. The housing fire prevention campaign anticipates a serious situation.

However, the number of actual house fire fatalities leveled off as indicated by the chart (Figure 2.6.5) representing a natural increase in the projected curve for the number of house fire fatalities based on 1985 and actual changes. This may be interpreted in many ways, one of which is that the number did not decrease in spite of the campaign for house fire prevention. However, there may have been a reason for the curtailment of the natural increase because what should

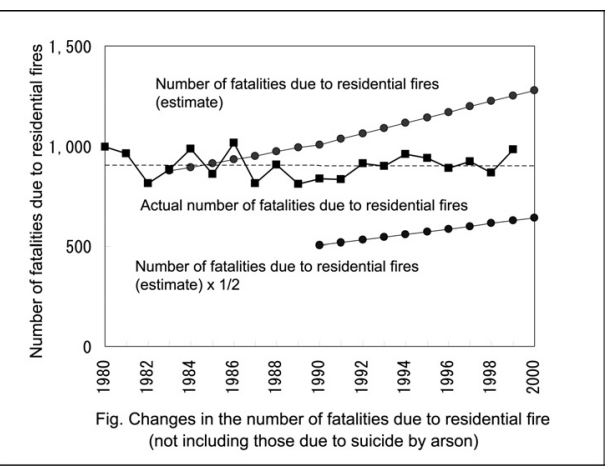
Figure 2.6.5 naturally have increased did not increase. And so, I studied this chart (Figure 2.6.6).

This is the number of age-specific fatalities among 1,000,000 people shown in chronological order. The upper portion represents those above 75 years old; the middle 65-74 years old. For example, the number of fatalities in the 65- to 74-year-old age group decreased by half between 1980 and 1992. The number of fire fatalities decreased by half of the population. The number in the age group above 75 years old decreased by approximately $40 \%$ from

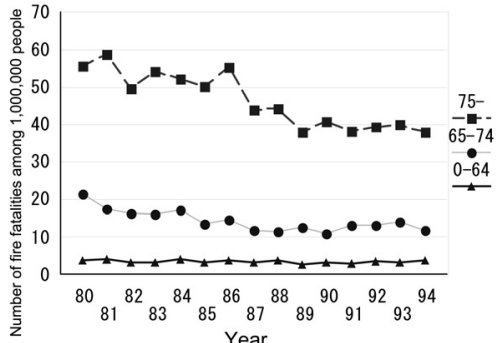

Fig. Age-specific changes in the number of fatalities due to residential fire (not including those due to arson or suicide by arson)

Figure 2.6.6

56 to 38. In other words, optimistically speaking, this may indicate that elderly people these days have become healthy and improved in responding to emergency situations. Human factors vary; however, damage may change according to the individual's physical condition. In fact, this may be an example of the significance of remaining healthy as far as minimizing fire damage is concerned.

Joining the National Research Institute of Fire and Disaster, I had opportunities to study many past fire cases. Human psychology and behavior during fire are points to be focused on today, and many fatalities are caused by failure to promptly evacuate from the area of the fire. Generally speaking, people do not evacuate promptly even upon hearing the fire alarm. Why? Failing to evacuate upon hearing an early fire alarm is a serious problem requiring improvement 
Professor Murosaki organized this chart. Considering evacuation actions analytically, the process from the start of the fire to evacuation may be divided into three categories: time to perceive the fire; time to prepare for the evacuation after perceiving fire; time required for the actual evacuation. Past examples of evacuation from fire indicate that the time to start evacuation is overwhelmingly long. Also, this is the critical factor. Professor Murosaki organized data

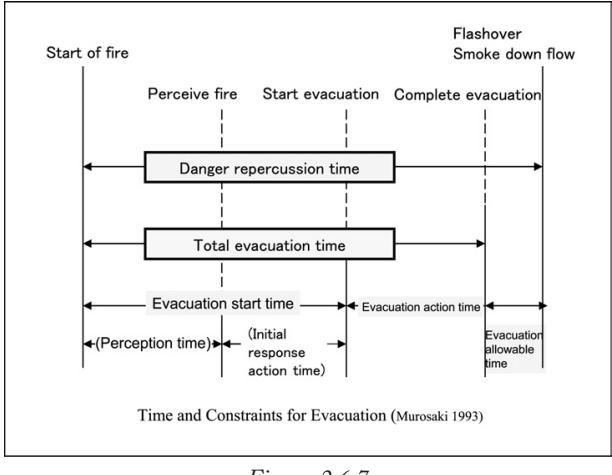
Figure 2.6.7 on 112 specific fire cases collected by the Tokyo Fire Department to obtain the mean time concerning evacuation. While the start of the fire to the start of evacuation was 6-8 minutes on average, the time to actually evacuate was $2-3$ minutes on average, indicating that the former requires proportionately much more time.

This chart is a mechanism of the relationship between perceiving fire and starting the evacuation, which Ebihara and Ikehata analyzed in greater detail. The previous examples show that people first perceive abnormalities, often by the auditory sense. Noises of people, sounds of crackling fire (with peculiar smells, however), etc., are audible and perceptible from a distance. However, this perception is followed by action to confirm information because

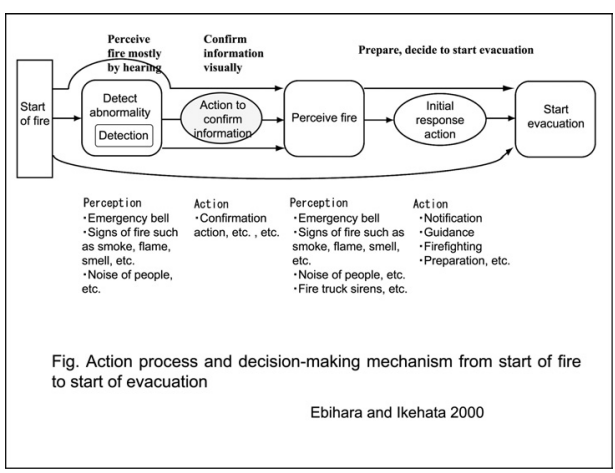

Figure 2.6.8 people invariably want to visually confirm information before deciding to evacuate. This basically means that people have a tendency to not evacuate until they see smoke. Also, the time from perceiving the fire to deciding to evacuate must be shortened; otherwise, even early perception of the signs of fire will not allow sufficient time for people to evacuate.

Furthermore, the first factor delaying evacuation is a mental process called "normalcy bias." This is a mental process to not recognize oneself in a serious situation; in other words, it is a tendency to maintain psychological peace. The second is underestimation due to the lack of proper knowledge of fire, which is the most critical. The third is that each piece of information on fire or smoke is confirmed visually. This has to be done more reasonably and efficiently. Improving these three points may shorten the evacuation time. 
Normalcy bias is depicted as a mental process of people who resist evacuation from fire or natural disaster. However, this is psychological resistance, which itself may be difficult to change.

Next, I would like to mention the Nagasakiya Store at Amagasaki (Figure 2.6.9). Perception of fire from the start of fire; in other words, confirmation of fire at the site (12:33) from the setting off of the fire alarm (12:32) was approximately 1 minute. Approximately 3 minutes later, a key person in the disaster control office on the fifth floor notified the fire department; another 2 minutes later, the fifth floor employee cafeteria, where many people died, was informed of the fire, leaving only 3 minutes to the time limit at approximately 12:40 when flashover was supposed to have taken place. Although there was enough time for evacuation considering the discovery of the fire, as many as 15 people died.

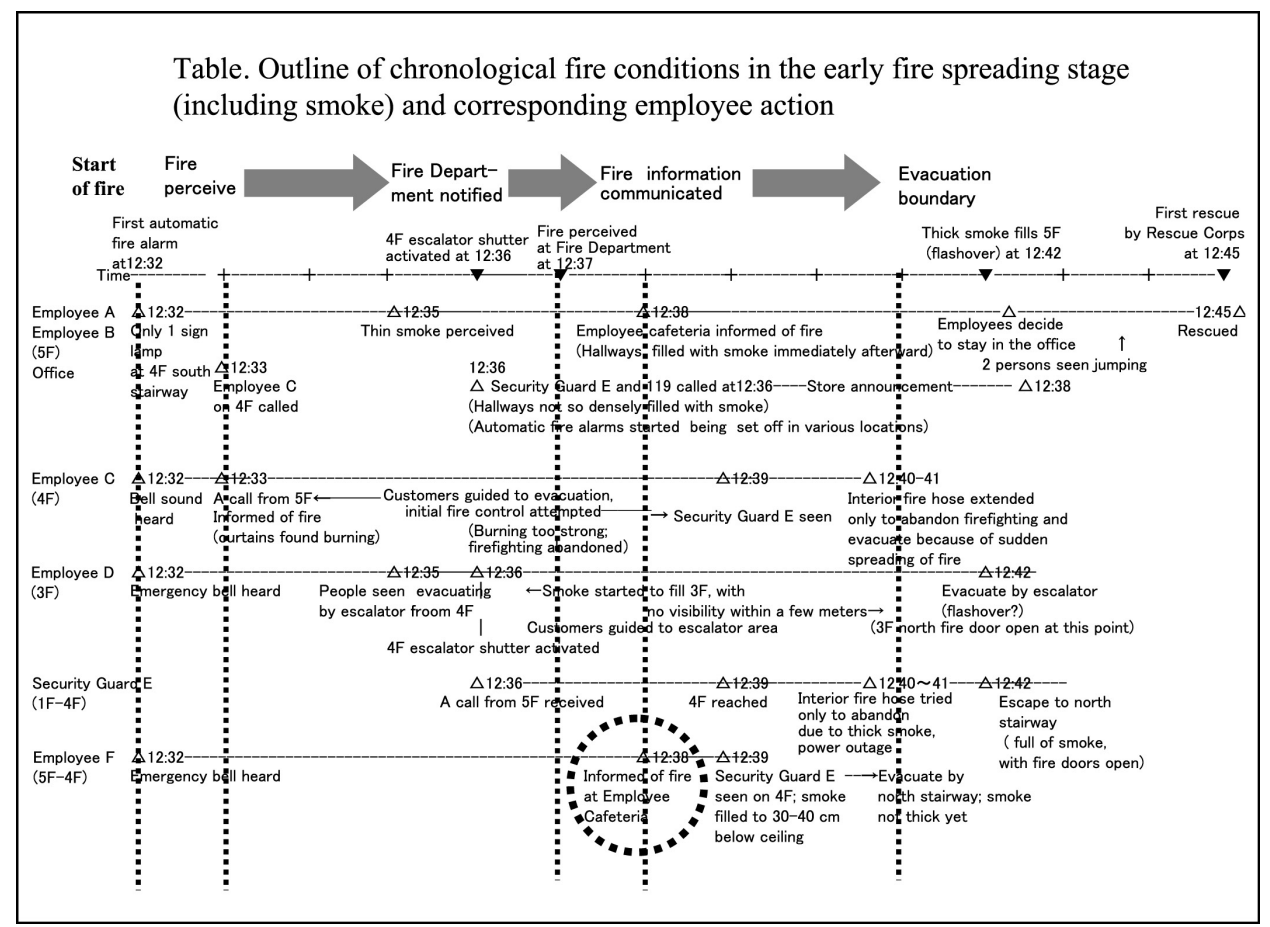

Figure 2.6.9

This figure (Figure 2.6.9) is marked with a circle at the bottom, which shows that only this employee survived by exiting from the fifth floor through the stairway after being informed of the fire. This person went down from the fifth floor, as explained later, not to evacuate but because of duty as a salesperson on the floor where the fire started. This may be interpreted as "role personality," an important key word, which is a concept watched very closely in the case of disaster prevention. In other words, one can act calmly in emergency situations if his role is properly determined. This applies to cases 
of uniformed staff, such as firemen, as well as this person. I am not an on-site fireman but a researcher at the National Research Institute of Fire and Disaster; however, after joining the Institute, I check emergency stairways whenever I stay at a hotel. I do this not just to escape alone but evacuate as many other people as possible; this awareness develops out of being at the workplace under the name of fire defense. Then, one may be able to act calmly and actively taking the initiative rather than being a bystander.

Finally, another point that I would like to emphasize is the "importance of properly knowing and fearing fire hazards." Many people may not be aware of the danger of fire or the rapid change during a flashover. I meant to present video images of a fire experiment, often shown at fire prevention lectures, to show the speed of a flashover; however, I hear that the images cannot be projected. I would like to conclude my talk here as my time is up, I'm afraid. 